\title{
O Silêncio da Família e da Escola Frente ao Desafio da Sexualidade na Adolescência
}

\section{The Silence of Family and School at the Challenge of Sexuality in Adolescence}

\section{Luciana Uchôa Barbosa ${ }^{1}$; Cátia Silene Carrazoni Lopes Viçosa ${ }^{2}$; Bernardina Santos Araújo de Sousa $^{3}$; Vanderlei Folmer ${ }^{4}$}

1 Doutoranda em Educação em Ciências, Instituto Federal de Pernambuco, Belo Jardim, Pernambuco, Brasil luciana.uchoa@belojardim.ifpe.edu.br ,/ORCID 0000-0002-3351-2075

2 Doutoranda em Educação em Ciências, Universidade Federal do Pampa, Uruguaiana, Rio Grande do Sul, Brasil catialopes00@ hotmail.com , / ORCID 0000-0002-6909-0839.

3 Doutora em Educação, Instituto Federal de Pernambuco, Belo Jardim, Pernambuco, Brasil bernardina.araujo@belojardim.ifpe.edu.br, /ORCID 0000-0002-8719-1588

4 Doutor em Ciências Biológicas, Universidade Federal do Pampa, Uruguaiana, Rio Grande do Sul, Brasil vanderleifolmer@unipampa.edu.br, / ORCID 0000-0001-6940-9080

\section{Recebido em 07/05/2018. Publicado em Agosto/2019}

Palavras-chave:

Sexualidade.

Adolescente. Professor. Família.

\section{Keywords:}

Sexuality. Teenager.

Teacher. Family.
RESUMO: Este trabalho objetivou pesquisar a concepção de educandos dos anos finais $\left(6^{\circ}\right.$ ao $\left.9^{\circ}\right)$ do ensino Fundamental, sobre sexualidade, a abordagem de pais ou responsáveis e a escola sobre essa questão, buscando identificar a principal fonte de informação sobre essas discussões. Assim como, identificar o desenvolvimento da educação sexual na escola. A pesquisa caracteriza-se por ser qualitativa, como instrumento de coleta de dados utilizou-se questionários com questões fechadas e abertas e a análise dos dados foi utilizada a Análise de Conteúdo de Bardin. Os resultados indicaram que a maioria das concepções sobre o que é sexualidade não condiz com o conceito científico do termo, relacionando - o ao ato sexual, infecções sexualmente transmissíveis e afetividade. Apontaram também que pais e responsáveis abordam essa questão de maneira tímida e com tabus e que as informações atuais que possuem sobre essa questão advêm de diversas fontes. Conclui-se assim, que o tema sexualidade, apesar ser amplamente discutido na academia, no espaço familiar, na educação básica e na sociedade como um todo são incipientes e distorcidas. Desta forma, percebeu- se uma abordagem fragilizada referente a sexualidade, direcionadas para os aspectos preventivos e biologizadas, perpetuando o silêncio das discussões acerca da sexualidade na adolescência. Sendo necessário ampliar as discussões sobre o conceito de sexualidade, na promoção da saúde e prevenção dos riscos e vulnerabilidades inerentes à adolescência.

ABSTRACT: This work aimed to investigate the conception of students from the final years (6th to 9th) of Elementary education, about sexuality, the approach of parents or guardians and the school about this issue, seeking to identify the main source of information about these discussions. As well as, identify the development of sex education in school. The research is characterized by being qualitative, as a data collection instrument was used questionnaires with closed and open questions and the data analysis was used the Bardin Content Analysis. The results indicated that most conceptions about what sexuality does not fit the scientific concept of the term, relating it to the sexual act, sexually transmitted infections and affectivity. They also pointed out that parents and guardians approach this issue in a timid and 
taboo manner and that the current information they have on this issue comes from a variety of sources. We conclude that the topic sexuality, although widely discussed in academia, family space, basic education and society as a whole are incipient and distorted. In this way, a fragilized approach regarding sexuality, directed to the preventive and biological aspects, was perceived, perpetuating the silence of the discussions about the sexuality in adolescence. It is necessary to broaden the discussions on the concept of sexuality, in the promotion of health and prevention of the risks and vulnerabilities inherent to adolescence.

\section{INTRODUÇÃO}

Discussões acerca da sexualidade são de extrema relevância, pois a insegurança dos adolescentes quanto a esse tema, associada à falta de informação, ainda prevalece, até mesmo, nos dias atuais. Diante dessa constatação, torna-se mister assumir compromissos educativos com a supracitada pauta, ou seja, torna-se urgente e necessário possibilitar ou fortalecer uma aproximação entre adolescentes e adultos de referência (professores/responsáveis e profissionais da saúde) a fim de reduzir as vulnerabilidades às Infecções Sexualmente Transmissíveis (ISTs), à gravidez não planejada, ao aborto inseguro, pois, é no decurso dessa trajetória que o adolescente passa por mudanças e enfrentamentos sociais, que poderão repercutir em sua vida, dependendo do contexto em que esteja inserido.

A urgente necessidade em favorecer a citada aproximação entre adolescentes e adultos de referência no trato com o tema, sexualidade, ocorre em virtude de que a adolescência, por representar uma fase de transição e fortes conflitos, entre a infância e a vida adulta, caracteriza-se como sendo fortemente marcada por intensas mudanças de natureza biopsicossocial.

Conforme Moreira e Folmer (2011), tais mudanças podem desencadear profundas tensões e inseguranças para os adolescentes, porque é nesse ínterim que esses indivíduos apresentam-se necessitados de que os adultos possam entender as questões que permeiam essa transição e enfim, acolhê-los e ouvi-los. A citação abaixo apresentada corrobora com essa discussão ao asseverar que:

\footnotetext{
A adolescência constitui-se em uma fase singular da vida, que está conectada a experiências da infância e às potencialidades inerentes ao indivíduo adulto, o que a caracteriza como um período de significativas transformações. Essa transitoriedade apoia-se na proposição de que a maior parte das experiências dos adolescentes esteja ligada à preparação para o ingresso na vida adulta (RESSEL et al., 2011, p.246).
}

Cabe ressaltar que dentre as modificações apresentadas na adolescência, destacam-se aquelas relacionadas à sexualidade. Assim, para Poersch et al. (2015), a adolescência é uma fase que envolve mudanças biopsicossocial marcada por conflitos com a própria imagem corporal, incluindo também à sexualidade. 
Ensino, Saúde e Ambiente-V.12 (2), pp. 31-49, Ago. 2019

Logo, a sexualidade é um componente intrínseco à pessoa, superando as fronteiras do biológico, revelando-se, também, como um fenômeno psicológico, cultural e social, influenciado pelas crenças, valores pessoais, familiares, normas morais e tabus da sociedade (NOTHAFT et al., 2014). Para Gonçalves et al. (2013) a educação sexual em um primeiro momento é de responsabilidade da família, devendo ter continuidade no espaço escolar, porém existe uma tendência de recuo de pais ou responsáveis diante da responsabilidade de educar sexualmente os/as adolescentes que estão sob sua tutela. Essa tendência pode estar relacionada ao fato de acreditarem que esses indivíduos não têm idade para falarem sobre o tema.

Diante desse contexto, Gonçalves et al. (2013) colaboram com a presente discussão ao apontarem que se faz necessário que os adultos reconheçam que, independentemente, da idade do/da adolescente, a sexualidade é uma dimensão inerente à vida humana, por isso, perpassa a trajetória de todo ser humano. Desse modo, as dúvidas dessa população, necessitam ser esclarecidas, assumidas e encaradas com responsabilidade, discutidas de maneira objetiva, orientando-a para que possa vivenciar a sua sexualidade de forma digna, responsável e segura.

Em Maciel et al. (2014), encontra-se sobre a proposta de uma educação sexual, a seguinte consideração:

Conhecer a realidade vivenciada e a percepção dos adolescentes sobre sua sexualidade deve ser o primeiro passo na elaboração de uma programação de ações educativas, problematizadoras e voltadas para o autocuidado corroborando uma proposta emancipatória, criativa e humanizada, correspondente à educação progressista, que rompe com a formação voltada para o modelo de assistência biomédico e autoritário (MACIEL et al., 2014, p. 67).

Quanto ao contexto escolar, houve um aumento na demanda por trabalhos na área da sexualidade, motivada pelo novo perfil sexual dos jovens e adolescentes, que têm se desenhado noutra perspectiva, marcada pelo início da vida sexual, que tem ocorrido cada vez mais precocemente, sem que ocorra a devida orientação. Consequentemente, esse fato tem ocasionado um notável crescimento no número de adolescentes que enfrentam uma gravidez não planejada, bem como, os riscos da contaminação pelo HIV e outras Doenças Sexualmente Transmissíveis (DSTs).

Na Europa, a educação sexual é contemplada nos currículos das escolas há mais de meio século (EUROPEAN EXPERT GROUP ON SEXUALITY EDUCATION, 2015). De acordo com Helmer et al. (2015), a Finlândia e a Holanda são conhecidas pelos consistentes programas de educação em sexualidade, tratados pela cultura escolar, como campo de 
Ensino, Saúde e Ambiente -V.12 (2), pp. 31-49, Ago. 2019

conhecimento. Esses países costumam apresentar baixas taxas de DSTs e gravidez na adolescência.

Diante do exposto, logo, percebe-se que a implementação da Educação Sexual já na adolescência, faz-se necessária a fim de promover atitudes e relacionamentos sexuais saudáveis, considerando que a mesma deverá compor um projeto de educação integral do indivíduo.

No Brasil, em termos de política curricular, a questão é tratada, timidamente, nos temas transversais, sob a denominação de Orientação Sexual. Entretanto, em pesquisa realizada por Lara et al. (2015), é notável a grande dificuldade que os professores têm em trabalhar, em seus conteúdos, questões relacionadas aos temas transversais, a interdisciplinaridade, a discussão sobre temas do cotidiano e de interesse dos alunos.

Na concepção de Savegnago e Arpino (2014) o tema sexualidade no espaço escolar assume uma considerável relevância no cenário contemporâneo:

Existe uma preocupação dos pais com os filhos perante os problemas da sociedade atual, mas eles não se sentem preparados para debater e conversar a respeito de questões relacionadas à sexualidade por considerá-las delicadas - o que a distância dos filhos adolescentes. Muitos acreditam que os professores estão mais preparados do que eles para trabalhar o tema da sexualidade com os adolescentes, e por isso delegam à escola essa tarefa (SAVEGNAGO e ARPINI, 2014, p. 928).

Corroborando, Martins et al. (2011), infere que no espaço escolar as práticas educativas favorecem reflexões e discussões que ampliam o campo de conhecimento ao abordar questões do seu cotidiano, entre elas, a sexualidade e as vulnerabilidades, geralmente, apresentadas nessa fase de vida, como por exemplo, à gravidez não planejada e o risco de contrair uma Infecção Sexualmente Transmissível. Nesse sentido, abordar a sexualidade como parte inseparável do sujeito, principalmente dos adolescentes, que estão em uma fase de curiosidade e descobertas, é permitir a esses sujeitos a oportunidade de entenderem e elaborarem suas vontades e desejos. Desta maneira, possibilitando, conforme Ferreira et al. (2014) a formação de cidadãos mais críticos e responsáveis consigo mesmos e com os outros.

Diante de tal contexto, o presente artigo é um recorte de uma pesquisa mais ampla, tecida no mestrado e doutorado, tendo por objetivo apresentar a concepção de adolescentes, vinculados à segunda etapa ou anos finais $\left(6^{\circ}\right.$ ao $\left.9^{\circ}\right)$ do ensino Fundamental, sobre sexualidade, contemplando, também, a abordagem de pais ou responsáveis e da escola sobre essa questão, identificar a principal fonte de informação sobre essas discussões, bem como verificar como são desenvolvidas as práticas docentes em educação sexual nas escolas pesquisadas. 


\section{METODOLOGIA}

Este estudo caracterizou-se como uma pesquisa de natureza qualitativa, envolvendo a observação participante, foi realizada em duas cidades interioranas, localizadas nos estados de Pernambuco e Rio Grande do Sul. Utilizou-se como ferramenta de coletas de dados o questionário, sendo um estruturado para os escolares e outro para os professores. Contemplaram perguntas abertas e fechadas, foram aplicados após a assinatura do Termo de Compromisso Livre e Esclarecido - TCLE, pelos professores e pais; o Termo de Assentimento, pelos/as adolescentes.

Destaca-se que quarenta e dois TCLEs foram entregues aos pais ou responsáveis, retornaram trinta e nove, devidamente assinados, autorizando a participação dos menores de idade na pesquisa. Sobre os três não autorizados, dois destes pais não autorizaram, alegando que seus filhos não tinham idade para falar sobre essa temática; o outro, faltou à escola no dia da aplicação dos questionários e entrega do termo autorizativo. Em relação aos docentes, participaram do estudo vinte e dois professores, vinculados a diferentes áreas do conhecimento.

Esta pesquisa atendeu à Resolução n 466/12 da Comissão de Ética do Conselho Nacional de Saúde sobre pesquisas envolvendo seres humanos e foi submetida ao Comitê de Ética em Pesquisa da Autarquia Educacional do Belo Jardim -AEB, para avaliação de sua viabilidade, tendo sido obtida aprovação por meio do Certificado de Apresentação para Apreciação Ética (CAAE) $n^{\circ}$ 30974514.6.000.5189 e Parecer de aprovação: 828.470 (09/10/2014).

As questões contempladas no instrumento de coletas de dados, elaborado para os escolares, foram estruturadas conforme demonstração no quadro abaixo:

\begin{tabular}{|l|l|}
\hline \multicolumn{1}{|c|}{ Questão } & \multicolumn{1}{|c|}{ Resposta } \\
\hline O que você entende por sexualidade? & ( ) Sim ( ) Não \\
\hline $\begin{array}{l}\text { Seus pais ou responsáveis conversam com você sobre } \\
\text { sexualidade? }\end{array}$ & \begin{tabular}{l} 
( ) Com pais ou responsáveis \\
\hline $\begin{array}{l}\text { As informações que você sabe sobre sexualidade amigos/as } \\
\text { hoje, você aprendeu? }\end{array}$ \\
( ) Na escola durante aula de diferentes disciplinas
\end{tabular} \\
\hline
\end{tabular}




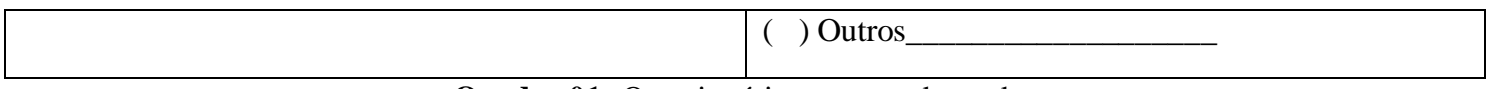

Quadro 01: Questionário para os educandos

Fonte: Elaborado pelos autores (2018)

Já as questões presentes nos questionários dos docentes foram estruturadas conforme quadro abaixo demonstrado:

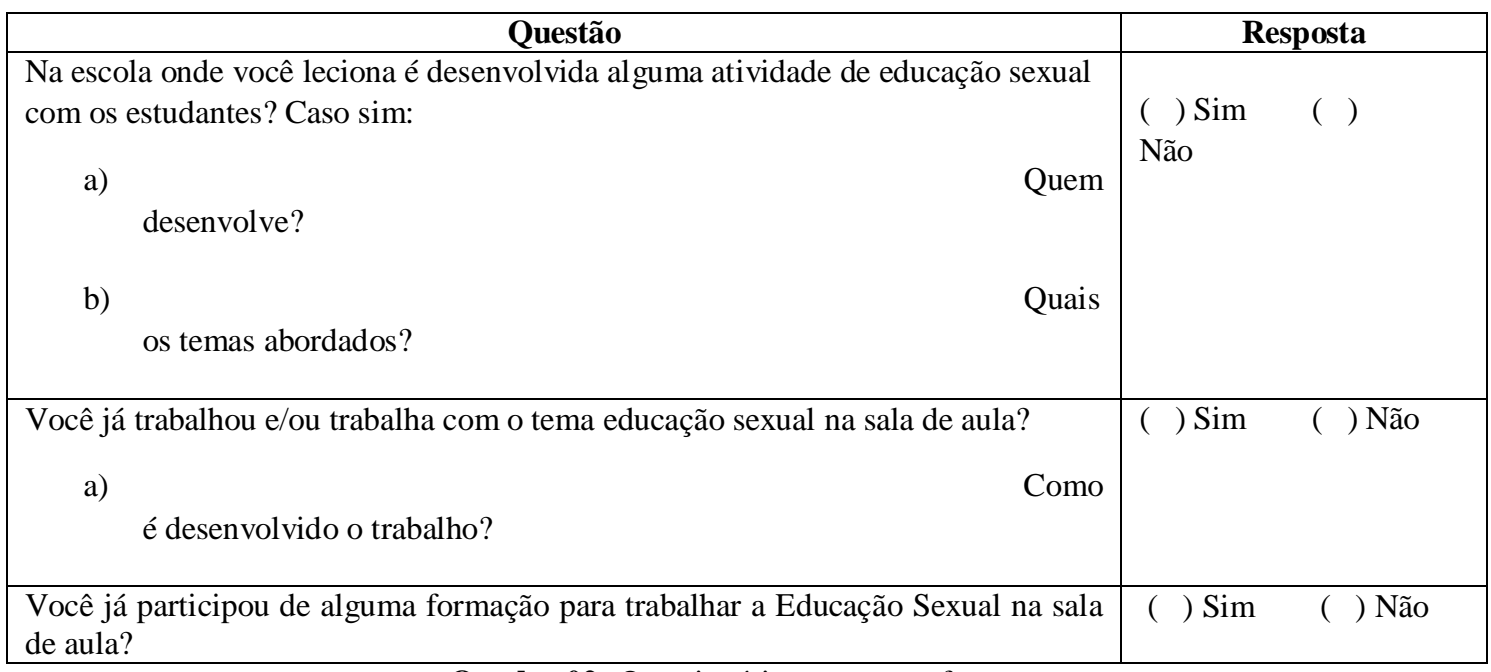

Quadro 02: Questionário para os professores

Fonte: Elaborado pelos autores (2018)

Os dados obtidos foram analisados conforme a técnica de Análise de Conteúdo de Bardin, considerando a pré-análise, exploração do material e tratamento dos resultados, inferência e interpretação (BARDIN, 2011). Para uma melhor compreensão dos resultados obtidos nesta pesquisa, a discussão teórica está dividida em quatro tópicos, adotando a seguinte ordem: Concepção sobre sexualidade; Diálogo sobre sexualidade no contexto familiar; Sexualidade no contexto escolar e finaliza com Abordagem sobre sexualidade no contexto escolar.

A análise dos questionamentos acerca da concepção sobre sexualidade, quem desenvolve a atividade de educação sexual na escola e quais os temas abordados foram apresentados em forma de nuvem de palavras, geradas através do software Wordart ${ }^{1}$, que tem a finalidade de buscar as palavras com maior incidência, apresentando-se com mais destaque na nuvem.

\section{RESULTADOS E DISCUSSÃO CONCEPÇÃO SOBRE SEXUALIDADE}

\footnotetext{
${ }^{1}$ Disponível em: https://wordart.com/ 
Ao analisarmos as respostas dos adolescentes pesquisados, pode-se evidenciar que a maioria relaciona a sexualidade, simplesmente, com o ato de fazer sexo, e também com gravidez e doenças. Nesse esforço, foi-nos possível constatar que é indispensável a presença de um adulto de referência para acolher as principais dúvidas dos adolescentes sobre sexualidade, tratá-las de modo a integralizá-las às outras dimensões do sujeito, numa perspectiva holística, ultrapassando os aspectos biológicos e reprodutivos e alcançando as dimensões, sociais, culturais e psicológicas que envolvem a existência desses sujeitos.

A maioria das concepções sobre o que é sexualidade, apresentadas por alguns participantes da pesquisa, não condizem com conceito científico do termo. Como demonstrado na nuvem de palavras abaixo apresentada, traduzem diferentes concepções, entre as principais, citam-se: relação sexual, gravidez, coisa perigosa e doenças.

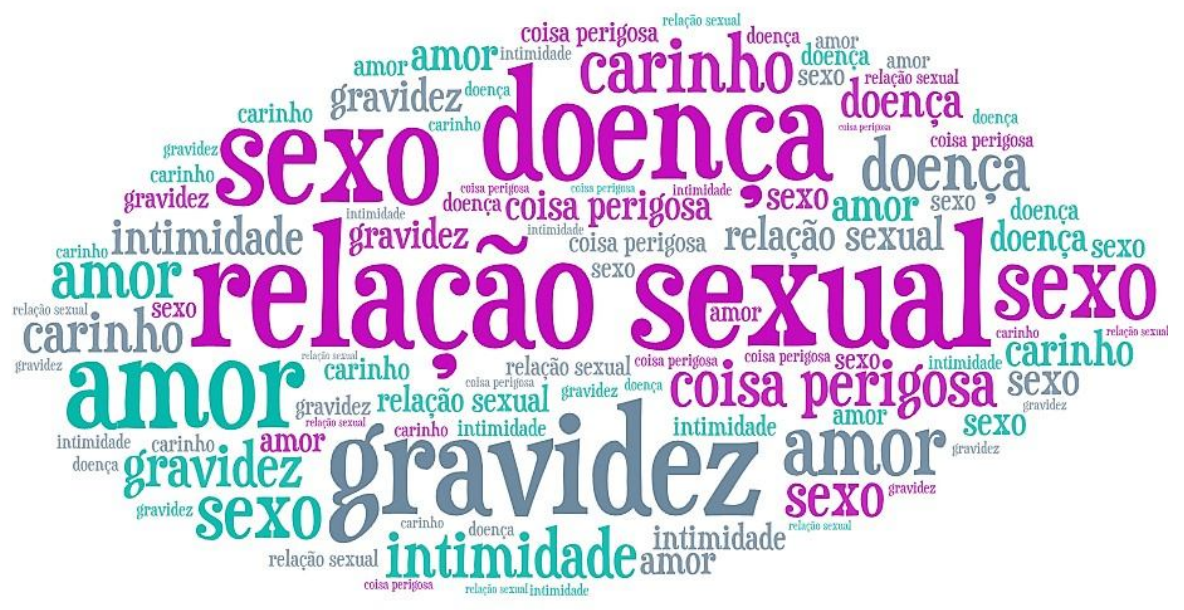

Figura 01: Nuvens de palavras associada as concepções dos adolescentes acerca da sexualidade Fonte: Elaborado pelos autores (2018)

Conforme Poersch et al. (2015) esta estreita relação do conceito de sexualidade apenas ao ato sexual e a reprodução humana é comum entre os adolescentes. Porém, os autores enfatizam que a sexualidade vai além do corpo e dos aspectos reprodutivos, pois envolve também valores, sentimentos, afeto. Nessa perspectiva, segundo Figueiró (2013), é essencial o adolescente adquirir informações acerca de sua sexualidade, ao longo do seu desenvolvimento, certamente, tal apropriação, traria consciência sobre essa relevante dimensão de sua vida, do seu próprio corpo, vinculando-se a uma perspectiva integradora de sujeito consciente dos seus desejos e responsabilidades, despertando para uma vivência prazerosa da sua sexualidade, livre dos tabus e culpas que continuam a envolver suas vidas.

Ainda neste contexto, Gonzalez et al. (2015), reiteram que a educação sexual proporciona às crianças e jovens conhecimentos, habilidades e valores que permitem 
assumirem comportamento mais saudáveis e uma vida sexual e social com mais responsabilidade.

A afetividade é outra concepção presente nas respostas dos alunos, sendo, deste modo, pertinente promover discussões acerca deste tema, esclarecendo a diferença entre sexualidade e afetividade. Na perspectiva de Heilborn (2012), destaca-se que:

\begin{abstract}
Afetividade e sexualidade, enquanto dimensões da pessoa, envolvem complexos processos de aprendizagem sociocultural e se atualizam cotidianamente através das formas sociais culturalmente convencionadas. O exercício da sexualidade pode encarnar a vontade de procriar, a satisfação do desejo, a demonstração de um estatuto social, ou um gesto que consolida uma relação afetiva. Estes diversos significados não são necessariamente excludentes, podendo haver um constante ajuste dos sujeitos em função do momento da trajetória biográfica (HEILBORN, 2012, p. 64).
\end{abstract}

Assim, compreende-se que os resultados obtidos demostraram que é de entendimento comum, dos (as) adolescentes partícipes, a ideia de sexualidade restrita à relação sexual e reprodução, não havendo um conhecimento mais amplo do seu significado.

Diante das respostas dos participantes, aponta-se a necessidade de esclarecer o conceito amplo de sexualidade. Para Gonçalves et al. (2013) muitas pessoas confundem o conceito de sexualidade com o do sexo propriamente dito, a sexualidade não se restringe às práticas sexuais. A sexualidade transcende o aspecto meramente biológico e reprodutivo, manifesta-se também como um fenômeno psicológico e social. Conforme Cabral e Romeiro (2011), lamentavelmente, a sexualidade humana está restringida a meras receitas de sexo perfeito, ao orgasmo fantástico (fetichista), ignorando toda possibilidade estética, ética e amorosa que envolve a sexualidade.

Apesar do tema sexualidade ter ganhado visibilidade a partir dos estudos de Freud, no início do século XX, e Michel Foucault, na década de 1980, predomina uma abordagem ainda voltada para características normativas (COSTA e COELHO, 2011). Para Foucault (1988) sexualidade é um dispositivo histórico através do qual age uma rede de superfície em que a estimulação dos corpos, a intensificação dos prazeres, a incitação ao discurso, a formação dos conhecimentos, o reforço dos controles e das resistências estão imbricados segundo estratégias de saber e poder.

Percebeu-se na fala de alguns poucos alunos,-uma noção razoável sobre a questão abordada, demonstrando que esses compreendem que a sexualidade perpassa pelo campo da descoberta do corpo biológico e social. Tal resultado dialoga com Carvalho (2013) quando este afirma que, para os adolescentes, a sexualidade se traduz em campo de descobertas, experimentações e vivência da liberdade, como também de construção de capacidade para a 
tomada de decisões, de escolha, de responsabilidades e de afirmação de identidades, tanto pessoais como políticas.

Na visão de Silva (2013), durante a adolescência, a sexualidade tem significado especial, visto que o indivíduo inicia a consolidação da sua identidade sexual e atinge a capacidade reprodutiva. Logo, ressalta-se que é indispensável compreender as concepções sobre sexualidade dos/as adolescentes, pois, tal compreensão irá contribuir para minimizar problemas no que tange às dimensões pessoal e social.

Salienta-se, também, que alguns participantes não souberam responder a questão por não se sentirem preparados, justificando não ter interesse pelo tema ou por possuir pouca idade para opinar.

Assim, é pertinente conhecer a dinâmica da sexualidade no contexto familiar e escola através da concepção dos adolescentes para, enfim, a partir desse conhecimento elaborar políticas e estratégias de atuação.

\section{DIÁLOGO SOBRE SEXUALIDADE NO CONTEXTO FAMILIAR}

Quanto à participação dos pais no processo de construção do entendimento e vivência da sexualidade, essa, apresenta-se de maneira tímida, cercada de mistérios e tabus. Os resultados abaixo apresentados são relacionados à existência de conversas ou diálogos sobre sexualidade, envolvendo pais ou responsáveis e adolescentes:

\begin{tabular}{|l|c|}
\hline Seus pais ou responsáveis conversam com você sobre sexualidade? & Respostas \% \\
\hline Sim & $50 \%$ \\
\hline Não & $47,37 \%$ \\
\hline Às vezes & $2,63 \%$ \\
\hline
\end{tabular}

Quadro 03: Resultado questão 02

Fonte: Elaborado pelos autores (2018)

Sobre essa abordagem Rocha e França (2013) inferem que os pais têm receio em dialogar com seus filhos sobre sexualidade por medo e falta de informações sobre o assunto. Além de pensarem que ao abordar o tema sexualidade, estarão incentivando, precocemente, seus filhos à prática sexual.

É provável que a forma como os pais foram educados sexualmente, e a falta de preparo sejam fatores impeditivos para a abordagem do tema sexualidade no contexto familiar, perpetuando-se, desse modo, a deseducação sexual. Pode -se inferir, ainda, que há 
uma influência de elementos culturais no contexto familiar, levando a afirmar que o diálogo entre os pais e a filha muitas vezes é limitado. Na visão de Maia et al. (2016):

Isso talvez demonstre que os responsáveis deixam de conversar sobre sexualidade com seus filhos, não por acharem desnecessário, mas sim por não saberem como abordar o tema de maneira natural e qual o momento em que se deve iniciar o assunto. Muitos acham que é necessário esperar o filho (a) vir com questionamentos primeiro para que o assunto seja abordado (MAIA et al., 2016, p. 74).

Um dos princípios básicos seria os pais ou responsáveis compreenderem melhor a fase de transição que envolve a adolescência, identificando a relevância do papel que devem desempenhar na relação com o adolescente, tentando auxiliá-lo a compreender melhor as mudanças demandadas por essa etapa da sua vida, incluindo-se aí o conhecimento da própria sexualidade.

A fuga a essa responsabilidade que deveria, a princípio, ser assumida em casa, pela família, bem como a ausência de compromisso curricular da escola com essa temática, acarretam no adolescente, a necessidade de recorrer aos seus pares, internet ou a mídia, buscando respostas às suas dúvidas e curiosidades, tendo o risco de acesso às nuvens de informações distorcidas, vulgarizadas, permeadas de tabus. Moreira e Folmer (2015), reiteram que os adultos têm um papel fundamental no acolhimento das dúvidas e/ou curiosidades dos adolescentes, contribuindo para potencializar as experiências e minimizar os riscos nesta fase da vida.

E complementando, Rogers et al. (2015), afirmam que a interação e o diálogo entre pais e filhos proporcionam confianças para ambos, especialmente quando abordam questões delicadas e comportamentais como o fenômeno da sexualidade. Nesse sentido, a influência familiar tem um impacto direto na compreensão e construção da sexualidade do adolescente, e que o conhecimento inseguro e os comportamentos sexuais, não orientados, podem levar à vulnerabilidade, tais como: às Doenças Sexualmente Transmissíveis, à Síndrome de Imunodeficiência Adquirida e à gravidez precoce (QUEIRÓS et al., 2016, p. 5120-5125).

\section{SEXUALIDADE NO CONTEXTO ESCOLAR}

O Quadro apresentado revela que apesar da necessidade premente de uma educação sexual no contexto escolar, e mesmo sendo, este, um consenso entre os estudiosos da área, observou-se nesta pesquisa que a escola não tem contribuído, de modo efetivo, para a construção do conhecimento sobre sexualidade e seus desdobramentos, conforme apontado no quadro abaixo:

As informações que você sabe sobre sexualidade hoje, você aprendeu?

Respostas (\%) 
Ensino, Saúde e Ambiente - V.12 (2), pp. 31 -49, Ago. 2019

\begin{tabular}{|l|c|}
\hline Com pais ou responsáveis & $18,43 \%$ \\
\hline Com seus/suas amigos/as & $18,43 \%$ \\
\hline Na escola durante aula de diferentes disciplinas & $5,26 \%$ \\
\hline Na igreja & $2,63 \%$ \\
\hline Outros & $10,52 \%$ \\
\hline Múltiplas escolhas & $44,73 \%$ \\
\hline
\end{tabular}

Quadro 04: Resultado questão 03

Fonte: Elaborado pelos autores (2018)

Observa-se que do total das respostas que indicaram mais de um item no questionamento, acima apontado como múltipla escolha, somente 5,26\% indicaram a escola, como fonte de informação, junto às demais opções apresentadas.

Brancaleoni e Oliveira (2016) ao afirmarem que a escola é um lugar de informação e formação, no qual estão presentes todas as áreas do conhecimento, reitera a importância e necessidade da educação sexual no contexto escolar, contemplada na pauta do currículo, abordada de maneira plena, considerando os aspectos biopsicossocial.

Entretanto, mesmo a escola sendo um espaço de saber legitimado socialmente, para tratar a questão da sexualidade, esta instituição apresenta dificuldades em lidar com o tema (BARROS E COLAÇO, 2013). Haja vista, ser esse tema, ainda tratado como tabu pela maioria das famílias, tornando delicada a sua abordagem em sala de aula, para Moreira e Folmer (2011), afirmam que trabalhar o tema sexualidade na escola é um grande desafio para os professores, requer coragem e conhecimento técnico para aborda-lo.

Nesse sentido, a fim de minimizar essas dificuldades, torna-se fundamental trabalhar desde a formação inicial dos futuros educadores, propostas interdisciplinares que utilizem temas transversais de relevância e urgência social (LARA et al., 2015).

Salles (2011) também aponta que a escola precisa ser vista como um espaço sexuado, e educação sexual seja tirada da marginalidade e colocada nas discussões curriculares. Nesta perspectiva podemos apontar como aliada a pedagogia de Paulo Freire (1987) que propõe um ensino baseado no diálogo, na liberdade e no exercício de busca do conhecimento, de forma participativa e transformadora, uma relação horizontal e de simpatia entre educando e educador.

Destarte, a educação sexual no espaço escolar e familiar vem se apresentando como uma intervenção necessária, uma vez que contribui para a construção da personalidade dos 
indivíduos e oportuniza questionamentos, reflexões e discussões que resgatam a marca humana da sexualidade: amor, afeto, favorecendo a qualidade nas relações sexuais e sociais.

\section{ABORDAGEM SOBRE SEXUALIDADE NA ESCOLA}

Em relação as respostas dos professores, quando indagados se na escola onde lecionam é desenvolvido alguma atividade de educação sexual com os estudantes, dos vinte e dois professores, dez responderam que sim, onze responderam que não, e um escreveu que está a pouco tempo na escola, então não sabe responder. Pelo resultado encontrado, percebese que a educação sexual na escola pesquisada não está consolidada e não envolve todos os docentes. Por outro lado, conforme Moreira e Folmer (2015), a educação sexual é necessária na escola porque tem como objetivo possibilitar, além de conhecimento e discussões sobre sexualidade, proporcionando uma vida com mais prazer e qualidade.

Quanto ao questionamento de quem desenvolve o tema educação sexual na escola em que eles trabalham, o professor de Ciências foi apontado como o maior protagonista desta prática docente, conforme figura 02 abaixo exposta. Esta constatação, conforme Furlani (2011), pode ser atribuída à historicidade da abordagem na qual a educação sexual na escola, muitas vezes exclusivamente, esteve presente nas aulas de Ciências e Biologia. Dessa forma Poersch et al. (2015), enfatiza que os assuntos sobre sexualidade devem ser trabalhados na sala de aula de maneira contínua e não somente em ações pontuais.

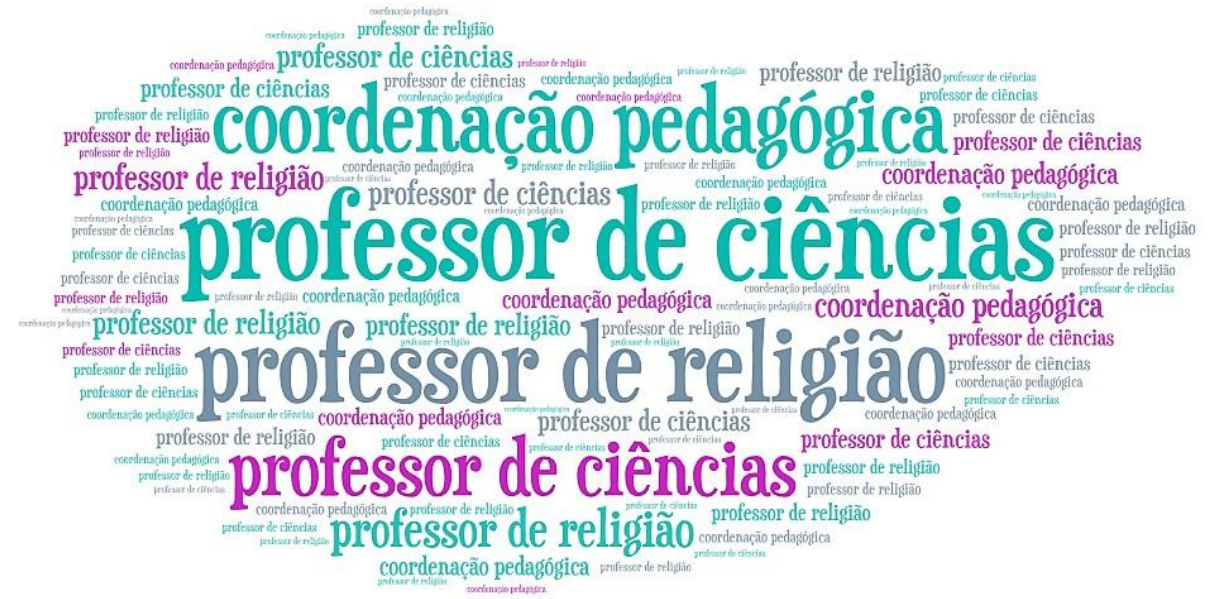

Figura 02: Associação a quem desenvolve educação sexual na escola

Fonte: Elaborado pelos autores (2018)

Logo, concordamos com Brancaleoni e Oliveira (2016) ao afirmarem que a escola é um lugar de informação e formação, no qual estão presentes todas as áreas do conhecimento. Na mesma direção, Queiroz et al. (2016) enfatiza que é necessário um diálogo feito por todos os professores independente da disciplina, baseado na transversalidade dos conteúdos. 
Analisando quais os assuntos são abordados quando se trabalha educação sexual na escola, fica evidenciado, pelas respostas dos professores e professoras na figura 03, que os assuntos são restritos às questões em torno da gravidez na adolescência e as DSTs.

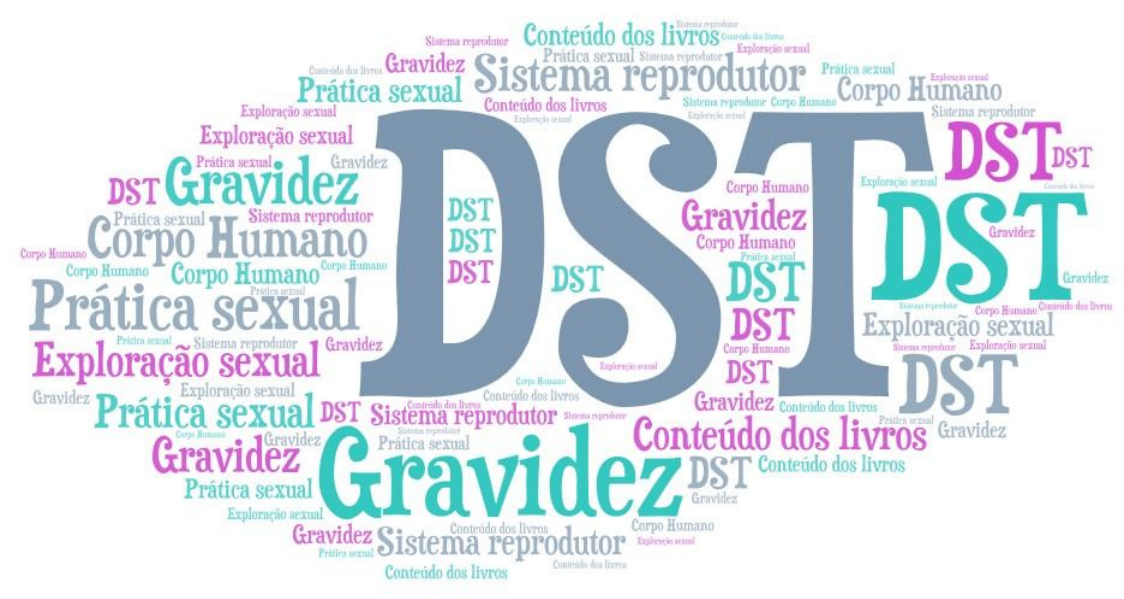

Nuvem de Palavras 03: Assuntos associados aos temas abordados em educação sexual Fonte: elaborado pelos autores, 2018

Sobre essa inferência, Sanchez (2012) afirma:

La escuela debe ofrecer una información sistemática sobre todos los temas fundamentales de sexualidad (anatomía, fisiología sexual y de la reproducción, afectos sexuales y sociales: deseo, atracción, enamoramiento, apego, amistad y sistema de cuidados), anticoncepción, etc (SANCHEZ, 2012, p.24-34).

Diante dos estudos descritos inferimos que o docente deve contribuir para a construção de uma expressão da sexualidade que valorize a promoção de saúde, o conhecimento das medidas preventivas e a valorização do sujeito adolescente por meio de ações que sejam fundamentais para a construção de uma autoestima saudável e equilibrada. Para tanto, esses profissionais devem ter uma visão crítica e aberta na sua ação como educadores de gerações que deverão se construir mais saudáveis, autônomas e conscientes das questões que envolvem as relações de gênero e sexualidade, assim Lanes et al. (2014) afirmam que:

Precisamos trazer os professores para uma educação sexual emancipatória, fazendoos refletir sobre os costumes repetidos acriticamente em nossa sociedade, questionando-os/as se os tabus, preconceitos e medos servem ainda para a realidade em que vivemos, tentando levar estes/as professores/as a falarem com naturalidade sobre a temática sexualidade (LANES et al., 2014).

No intuito de buscar novos referenciais, além da América do Sul, sobre discussões referentes a temática discutida, apresentamos a conclusão de estudo realizado em Território do Norte, Austrália Ocidental e na Austrália do Sul que teve como sujeitos de pesquisas 
jovens estudantes. Os dados conforme Helmer et al. (2015) apresentam indicativa que os jovens percebem que precisam de mais conhecimento para ter relacionamentos saudáveis.

Os participantes apontam que as formas atuais de educação em sexualidade são muito clínicas, didáticas e desinteressantes, e estão ausentes no conteúdo relevante. Os jovens solicitaram mais informações sobre relacionamentos, primeiras experiências sexuais e negociação do uso de preservativos. Essas solicitações indicam que os jovens percebem que precisam de mais conhecimento para ter relacionamentos saudáveis, o que entra em conflito com a crença popular de que fornecer aos jovens informações honestas e abertas sobre sexo encoraja-os a fazer sexo ou aumentar o risco sexual. Tornar a educação sexual mais prioritária e ouvir as necessidades dos jovens pode ser um passo positivo para melhorar a saúde sexual e o bem-estar. (HELMER et al., 2015).

Quanto à questão se os professores trabalham ou já trabalharam a educação sexual, onze responderam que não trabalham, nove trabalham e dois responderam que já trabalharam essas questões com o Ensino de Jovens e Adultos (EJA). Quanto ao método que utilizaram, os professores elencaram as palestras, filmes e livros do da própria disciplina. Assim, podemos inferir que a transmissão de conhecimento tem sido a metodologia mais utilizada, sendo os estudantes meros receptores de informações, sem uma discussão e reflexão criativa.

Almeja-se que o fazer docente transcenda a mera transmissão/reprodução de informações aos estudantes, englobando a produção e o debate sobre conhecimentos científicos de modo que os mesmos façam sentido aos estudantes e professores (ORLANDI $e t$ al., 2017). Nesse mesmo contexto, Freire (1987) infere que ensinar não é transferir conhecimento, mas criar as possibilidades para sua própria produção ou a sua construção, portanto é preciso refletir a nossa prática enquanto educadores. Logo, a educação sexual deve utilizar uma estratégia de ensino participativa que envolve os adolescentes no pensamento crítico sobre sua sexualidade.

Com base no exposto, percebe-se que os professores não estão preparados para abordarem temas relacionados a educação sexual. Esta inferência ganha força ao analisar que dos vinte e dois professores participantes deste estudo, vinte e um responderam que não receberam formação para trabalhar a Educação Sexual na sala de aula.

O padrão de resposta observado não se restringe apenas aos professores e professoras desta pesquisa. O resultado da pesquisa realizada por Gesser et al. (2015) com o objetivo de identificar as concepções de sexualidade de docentes que atuam na rede de educação básica, identificaram que as professoras e os professores participantes da pesquisa, na sua maioria, não tiveram acesso à formação inicial e nem à formação continuada relacionada às temáticas gênero e sexualidade. 
Ensino, Saúde e Ambiente-V.12 (2), pp. 31-49, Ago. 2019

Logo, concordamos com Santos et al. (2016), ao ressaltar que à escola deve investir na formação continuada dos seus educadores, a fim de aprimorar a sua qualificação. Assim como é necessário investir na formação iniciada e continuada com vistas à formação de educadores sexuais que atuem na linha da abordagem emancipatória (QUIRINO e ROCHA, 2012).

Sobre essa inferência, Zerbinati e Bruns (2017) ressaltam o papel do profissional qualificado e motivado no ensino da sexualidade, podendo contribuir na organização das

relações e discursividades humanas para que a educação sexual se fortaleça enquanto disciplina multidisciplinar, científica e popular.

Diante do exposto, ressaltamos que a escola deve estar preparada para fornecer informações cientificamente precisas, realistas e sem julgamentos.

\section{CONSIDERAÇÕES FINAIS}

Embora o tema sexualidade já tenha sido amplamente discutido na academia, o espaço nas discussões familiares, na educação básica e na sociedade como um todo são incipientes e distorcidas. Os resultados demonstraram que a abordagem ocorre de maneira frágil, direcionada para os aspectos preventivos e biologizadas e certo receio pelos adultos de referência (pais, responsáveis, professoras e professores e profissionais de saúde), perpetuando o silêncio das discussões acerca da sexualidade na adolescência.

Neste sentido, faz-se mister avançar nas discussões, o conceito amplo de sexualidade e suas influências culturais, assim como as questões dos direitos humanos, sem nos distanciarmos das questões de promoção da saúde e prevenção dos riscos e vulnerabilidades inerentes à adolescência. Logo, entendemos que os pais, professores e profissionais de saúde devem possibilitar aos adolescentes uma educação sexual baseada no diálogo aberto, promovendo um ambiente seguro e acolhedor.

Considerando a relevância desta temática, e sobretudo as carências encontradas neste estudo pretende-se continuar contribuindo com os trabalhos desenvolvendo novas pesquisas, inserindo como sujeitos os adultos de referência. Especificamente, nossa proposta é realizar atividades que envolvam em um mesmo ambiente, os adultos de referência para a discussão e reflexão de como e quando devemos abordar educação em sexualidade com adolescentes. Assim como, realizar pesquisas para analisar os Planos Nacional e Estaduais de Educação propondo caminhos e avaliando as formas que os Estados (Pernambuco e Rio Grande do Sul) 
Ensino, Saúde e Ambiente - V.12 (2), pp. 31-49, Ago. 2019

estão trabalhando as questões de sexualidade na Educação Básica, inclusive, as concepções dos adultos de referência e a influência na educação em sexualidade.

\section{REFERÊNCIAS}

BARDIN, L. Análise de conteúdo. 3 ed. Lisboa: Edições 70, 2011.

BARROS, J. P. P.; COLAÇO, V. F. R. Meu prazer agora é risco: sentidos sobre sexualidade entre jovens de um grupo sobre saúde. Fractal, Revista de Psicologia. v. 25, n. 1, p 59 80,2013 .

BRANCALEONI, A. P. L.; OLIVEIRA, R. R. Educação sexual na promoção do respeito à diversidade sexual e de gênero. ELO Diálogos em Extensão, v.5, n. 2, p. 57- 62, 2016.

CABRAL, R. V.; ROMEIRO, A. E. Sobre a sexualidade controlada: poder e repressão sexual em Michel Foucault. Revista Educação, vol. 1, n. 1, p. 87-106, 2011.

CARVALHO, A. O. Adolescentes no contexto de uma comunidade: perspectivas para o cuidado de enfermagem. 2013, 112p. Dissertação de Mestrado: UFPI, Teresina/PI. Disponível em http://leg.ufpi.br/mestenfermagem/index/pagina/id/6308. Acessado em novembro de 2017.

COSTA, L. H. R.; ALMEIDA, E. C. Nursing and sexuality: Integrative review of papers published by the Latin-American Journal of Nursing and Brazilian Journal of Nursing.

Revista Latino-Americana de Enfermagem, v. 19, n. 3, p. 631-639, 2011.

FERREIRA, G.; ARAÚJO, C. W.; OLIVEIRA, K. A. Gênero, sexualidade e orientação sexual em Senhor do Bonfim /BA. Revista Extendere, vol. 02, n. 01, p. 166-176, 2014.

FIGUEIRÓ, M. N. D. Educação sexual no dia a dia. Londrina: EDUEL, 2013.

FREIRE, P. Pedagogia do oprimido. 17ª Edição. São Paulo: Paz e Terra, 1987.

FOUCAULT, M. História da sexualidade I: A vontade de saber. 19. ed. Tradução de: Maria Thereza da Costa Albuquerque e J. A. Guilhon Albuquerque. Rio de Janeiro: Edições Graal, 1988.

GESSER, M.; OLTRAMARI, L. C.; PANISSON, G. Docência e concepções de sexualidade na educação básica. Revista Psicologia e Sociedade, v.27, n.3, p. 558-568, 2015.

GONÇALVES, R. C.; FALEIRO, J. H.; MALAFAIA, G. Educação sexual no contexto familiar e escolar: impasses e desafios. Revista Holos, vol. 29, n. 05, p. 251-263, 2013.

GONZALEZ, A. E.; MOLINA, G. T.; LUTTGES, D. C. Características e la educación sexual escolar recibida y su asociación con la edad de inicio sexual y uso de anticonceptivos en adolescentes chilenas sexualmente activas. Revista Chilena de Obstrecia Gnecologica, v. 80, n. 1, p. 24-32, 2015.

HEILBORN, M. L. Por uma agenda positiva dos direitos sexuais da adolescência. Revista Psicologia Clínica, v. 24, n.1, p. 57-68, 2012.

HELMER, J.; SENIOR, K.; DAVISON, B.; VODIC, A. Improving Sexual Health for Young People: Making Sexuality Education a Priority. Sex Education: Sexuality, Society and Learning, v.15 n.2 p.158-171, 2015.

MAIA, T. Q.; SOARES, L. O.; VALLE, P. A. S. S; MEDEIROS, V. M. G. Educação para sexualidade de adolescentes: experiência de graduandas. Nexus- Revista de Extensão do IFAM, v. 02, n. 02, p. 71- 78, 2016. 
Ensino, Saúde e Ambiente -V.12 (2), pp. 31-49, Ago. 2019

MACIEL, J. A. C.; ROCHA, S.; ALVES, J. G.; CARVALHO, Q. M.; BARBOSA, F. B.; TEIXEIRA, A. M. Sexualidade na adolescência: dialogando e construindo saberes através do pet saúde/redes de atenção no município de Sobral - Ceará. Sanare-Revista de Políticas Públicas, v. 13, n. 01, p. 64-68, 2014.

MARTINS, C. G.; FERREIRA, L. O.; SANTOS, P. M.; LOPES SOBRINHO, M.; WEISS, M. C.; SOUZA, S. S. Oficina sobre sexualidade na adolescência: uma experiência da equipe saúde da família com adolescentes do ensino médio. Revista Mineira de Enfermagem, v.15, n. 4 , p. $573-578,2011$.

MOREIRA, B. R.; FOLMER, V. Educação Sexual na Escola: construção e aplicação de material de apoio. Revista Experiência em Ensino de Ciências, v. 6, p.151 - 160, 2011.

MOREIRA, B. R.; FOLMER, V. Percepções de professores de ciências e educação física acerca da educação sexual na escola. Revista Experiência em Ensino de Ciências, v.10, n. 3, p.18-20, 2015.

NOTHAFT, S.; ZANATTA, E.; BRUMM, M. L.; GALLI, K.; ERDTMANN, B.; BUSS, E.; SILVA, P. Sexualidade do adolescente no discurso de educadores: possibilidades para práticas educativas. Revista Mineira de Enfermagem, v.18. n. 02, p. 284-289, 2014.

POERSCH, K. M.; KLIEMANN, B. C. K.; LIMA, B. G. T. Reflexões sobre o trabalho com sexualidade no Ensino Fundamental: desafios e possibilidades. Revista Ensino, Saúde e Ambiente, v. 8, n.02, p. 37- 49, 2015.

RESSEL, L.; JUNGES, C. SEHNEM, G.; SANFELICE, C. A influência da família na vivência da sexualidade. Escola Anna Nery, v.15, n. 02, p. 245- 250, 2011.

ROCHA, M. B.; FRANÇA, G. A. Gênero e sexualidade: como os licenciandos em Ciências Biológicas concebem esses temas? Revista Ensino, Saúde e Ambiente, v. 06, n 01, 2013.

ROGERS, A.; HA, T.; STORMSHAK, E.; DISHION, T. Quality of parent-adolescent conversations about sex and adolescent sexual behavior: an observational study. J Adolesc Health. v.57, n 02, p. 174-178,2015. Disponível em https://doi.org/10.1016/j.jadohealth.2015.04.010. Acessado em fevereiro de 2018.

SANCHEZ, L. 2012. Educación Sexual em la familia y la escuela. Revista Elo do Centro de Formação Francisco de Holanda: A educação Sexual na escola, v. 19, n. 19, 2012. Disponível em https://www.cffh.pt/. Acessado em abril de 2017.

SAVEGNAGO, S. D. O.; ARPINI, D. M. Conversando sobre sexualidade na família: olhares de meninas de grupos populares. Caderno de Pesquisas, v. 43, n. 150, p. 924- 947, 2014.

SILVA, V. M. Percepções de adolescentes escolares sobre a iniciação sexual. 2013. Dissertação Pós-Graduação em Saúde da Criança e do Adolescente do Centro de Ciências da Saúde da Universidade Federal de Pernambuco, Recife/PE. Disponível em https://repositorio.ufpe.br/handle/123456789/13404. Acessado em dezembro de 2015.

QUEIROZ, A.; SOUSA, A.; FEITOSA, J.; ALVES, R.; NERY, I.; MOURA, M. Educação sexual para adolescentes por docentes de um centro de educação comunitária. Revista Online de Pesquisa Cuidado é Fundamental, v. 8, n. 4, p. 5120-5125, 2016.

ZERBINATI, J. P.; BRUNS, M. A. T. Sexualidade e educação: revisão sistemática da literatura científica nacional. Revista Travessias, Cascavel, v. 11, n.1, p. 76-92, 2017. 
Ensino, Saúde e Ambiente -V.12 (2), pp. 31-49, Ago. 2019

\section{LUCIANA UCHÔA BARBOSA}

Doutoranda do Programa de Pós Graduação Educação em Ciências: Química da Vida e Saúde - UFRGS. Mestra em Educação em Ciências: Química da Vida e Saúde - UFRGS. Possui graduação em Enfermagem pela Fundação de Ensino Superior de Olinda União de Escolas Superiores da FUNESO. Especialização em Educação Profissional na área de Enfermagem e Especialização em Saúde Pública. Docente do Instituto Federal de Educação, Ciência e Tecnologia de Pernambuco - Campus Belo Jardim. Coordenadora do curso Técnico de Enfermagem do Instituto Federal de Educação, Ciência e Tecnologia de Pernambuco Campus Belo Jardim. Membro do Núcleo de Estudos sobre Gênero e Diversidade. Tem experiência na área de Enfermagem e Educação, com ênfase em: Atenção Básica, Saúde Pública, atuando principalmente nos seguintes temas: Saúde da Mulher; Saúde da Criança e Adolescente; Educação em Saúde; Programa Nacional de Imunização; Programa de Hipertensão e Diabetes.

Participação na elaboração do estudo apresentado: Levantamento bibliográfico, submissão do projeto ao Plataforma Brasil, coleta dos dados, organização, análise e discussões dos resultados.

\section{CÁTIA SILENE CARRAZONI LOPES VIÇOSA}

Doutoranda em Educação em Ciências: Química da Vida e Saúde- Unipampa; Mestra em Educação em Ciências: Química da Vida e Saúde - UFSM; Especialista em Educação Especial e Inclusiva - FAEL; Graduada em Ciências da Natureza Licenciatura, Unipampa/Campus Uruguaiana. Participa do Grupo de Pesquisa e Estudos em Nutrição, Saúde e Qualidade de Vida (Gensq). Possui interesse na área do estudo da Interdisciplinaridade, Transversalidade, Integração e Contextualização dos Saberes no contexto escolar, nas áreas de Educação Ambiental, Educação Patrimonial e Educação Inclusiva.

Participação na elaboração do estudo apresentado: Levantamento bibliográfico, coleta dos dados, organização, análise e discussões dos resultados

\section{BERNARDINA SANTOS ARAÚJO DE SOUSA}

Doutora em Educação pela Universidade Federal da Paraíba; Mestra em Educação pela Universidade Federal de Pernambuco; Especialista em História do Brasil; Especialista em Sociologia; Graduada em Licenciatura Plena em Pedagogia pela Faculdade de Filosofia Ciências e Letras de Caruaru; Docente do Instituto Federal de Pernambuco, professora do curso de Licenciatura em Música do Campus Belo Jardim; vice coordenadora Local do Mestrado Profissional em Educação Profissional do IFPE (ProfEPT); Membro do Núcleo Docente Estruturante do Curso de Licenciatura em Música e do Núcleo de Estudos sobre Gênero e Diversidade. Pesquisadora na área de Currículo e Cultura; Práticas Pedagógicas em Espaços educacionais Formais e não formais; Relações de Gênero e Educação; Inclusão e Diversidade em espaços formais e não formais de ensino em EPT. Coordenadora do Grupo de Pesquisa Práticas Culturais, Música e Sociedade.

Participação na elaboração do estudo apresentado: Levantamento Bibliográfico, análise e discussões dos resultados.

\section{VANDERLEI FOLMER}

Pós doutorado em Bioquímica Toxicológica (Universidade de Lisboa-Portugal); Doutor em Ciências Biológicas (Bioquímica Toxicológica) pela Universidade Federal de Santa Maria; 
Mestre em Educação em Ciências: Química da Vida e Saúde pela Universidade Federal do Rio Grande do Sul, graduação em Letras - Português e Inglês pela Universidade Paulista; Graduado em Fisioterapia pela Universidade Federal de Santa Maria; Docente da Universidade Federal do Pampa - Campus Uruguaiana. Coordenador do Grupo de Pesquisa e Estudos em Nutrição, Saúde e Qualidade de Vida (Gensq). Tem experiência nas áreas de Educação em Ciências e Bioquímica, atuando principalmente nos seguintes temas: Educação em Saúde, Interdisciplinaridade no Ensino de Ciências, Bioquímica de Produtos Naturais e Diabetes mellitus.

Participação na elaboração do estudo apresentado: Levantamento Bibliográfico, análise e discussões dos resultados e revisão da escrita. 